\title{
Voltinism, Seasonal Reproduction, and Diapause in the Squash Bug (Heteroptera: Coreidae) in Kansas
}

\author{
JAMES R. NECHOLS \\ Department of Entomology, Kansas State University, \\ Manhattan, Kansas 66506
}

\begin{abstract}
Environ. Entomol. 16: 269-273 (1987)
ABSTRACT The squash bug (SB), Anasa tristis DeGeer, completes 1.5 generations per yr in northeastern Kansas. Overwintered adults mate and oviposit on cucurbitaceous host plants from early June to mid-August. Most eggs are deposited from June to early July when female survivorship is highest, but some oviposition occurs through mid-August. First-generation adults begin to emerge between the 1st and 3rd wk of July. Oviposition commences 7-10 d after emergence. Females that emerge before late July avoid diapause and produce a second generation. Thereafter the incidence of diapause increases progressively, reaching $100 \%$ in first- and second-generation females that emerge in early September. Diapausing females do not mate or reproduce until the following spring. SB males also appear to undergo diapause but, unlike females, they overwinter with mature reproductive organs. The primary expression of male diapause is suppressed reproductive behavior. Reproductive periods of overwintered and first summer-generation adults overlap. The extent of this overlap depends in part on spring temperature conditions that influence field entry by overwintered adults; the oviposition schedule; and development of first-generation progeny. During cool springs, a large proportion of first-generation SB emerge late in the season and enter diapause. In these years, smaller, less-damaging, populations occur.
\end{abstract}

KEY WORDS Anasa tristis, voltinism, diapause, reproduction

The SQUaSh bug (SB), Anasa tristis DeGeer, is an important indigenous pest of squash, pumpkins, and other vine crops in the genus Cucurbita thoughout most of the United States. Despite its widespread importance and broad North American range, literature on the biology of this insect is limited to only a few early life-history investigations by Beard (1940) and Elliot (1935) in Connecticut and Worthley (1923) in Massachusetts. Consequently, very little is known about SB biology or ecology in the Midwest, where it is a particularly serious pest. In addition, no previous studies of this insect's dormancy have been made.

Insect seasonal cycles vary geographically and these differences have important implications for the development of pest management programs at the regional level (see Tauber et al. [1986]). Therefore in this paper I examine various aspects of the seasonal biology of a midwestern population of SB. Specifically, my objectives were to determine the seasonal occurrence and number of generations completed by SB annually; the seasonal oviposition pattern and survivorship of overwintered adults; and the natural onset of diapause in the field. Because the expression of insect diapause may differ between sexes (see Pener \& Orshan [1983]), male bugs were evaluated separately from females.

\section{Methods and Materials}

Seasonal Occurrence. To determine the first incidence of overwintered SB adults on host plants, fields containing cultivated or wild cucurbits were surveyed visually at various locations in northeastern Kansas beginning in May during 1984 and 1985. This period coincided with common planting dates of squash and zucchini and was also associated with the appearance of a naturally occurring weed, Cucurbita foetidissima H.B.K.

In 1985, greenhouse-grown zucchini plants ( $C$. pepo L., 'Zucchini Elite') were transplanted to the border of a pumpkin field located near Manhattan, Kans., in early May (i.e., before the commercial planting date). These were monitored about twice weekly for the presence of SB adults.

Voltinism. To establish the number of generations completed by $A$. tristis, first-generation fourth and fifth instars (from overwintered adults) were field-collected in mid-July 1984 and confined in a screened frame cage $(0.47$ by 0.47 by $0.47 \mathrm{~m})$ in a commercial field of summer squash (C. maxi$m a$ ). Similar procedures were used in 1985, except that first-generation SB were reared on zucchini plants from the earliest field-collected eggs that were found.

In both years, first-generation adults mated and oviposited in the cages. Subsequently, second-generation eggs were transferred to modified screened cages that were covered with a layer of nylon organdy (to prevent the entry of small first-generation nymphs). After hatching, these were allowed to develop. In 1985, observations were made about every second day to estimate the proportion of each life stage present throughout the season. Ob- 


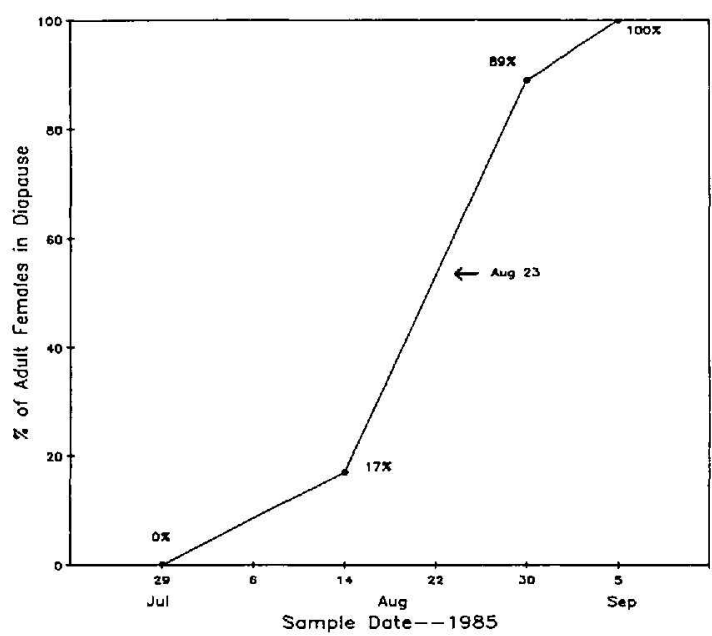

Fig. 1. Percentage of $A$. tristis females in reproductive diapause on each sample date. Samples were made 1 wk after the median field emergence date. Arrow indicates the predicted date on which $50 \%$ of the population is in diapause. The numbers of individuals (n) for each sample date are as follows: 29 July (22), 14 August (29), 30 August (18), 5 September (38).

servations continued until all reproduction and development ceased in autumn.

Reproduction and Survivorship in the Field. To determine the period of reproductive activity and survivorship for overwintered SB, 25 mated females were placed in wire-mesh frame cages over transplanted zucchini plants ('Zucchini Elite') within 2 wk of their entry into the field in 1985. The number of surviving adult females and the total number of eggs were recorded every 3-6 d. At each check, the egg masses were removed or the caged adults were transferred to new, uninfested host plants. This procedure was continued until all female bugs had died.

To compute the average daily oviposition per female, the total number of eggs found on each date was divided by the number of days from the previous observation date, and by the number of females alive at the beginning of each interval. Survivorship was computed as the proportion of females alive on each observation date.

Onset of Diapause in the Field. To assess the seasonal incidence of reproductive diapause in SB, groups of field cage-reared first summer-generation adults were obtained at various intervals by collecting egg masses deposited by large number of females periodically from early June to later July 1985. Each group of adults ( $n=18-38$ pairs) was transferred to the laboratory $1 \mathrm{wk}$ after the time of median emergence (this period allowed for full development of either a reproductive or diapause condition). The sample dates are shown in Fig. 1.

On the 29 July and 14 August sample dates, individual SB pairs (female and male) were trans-

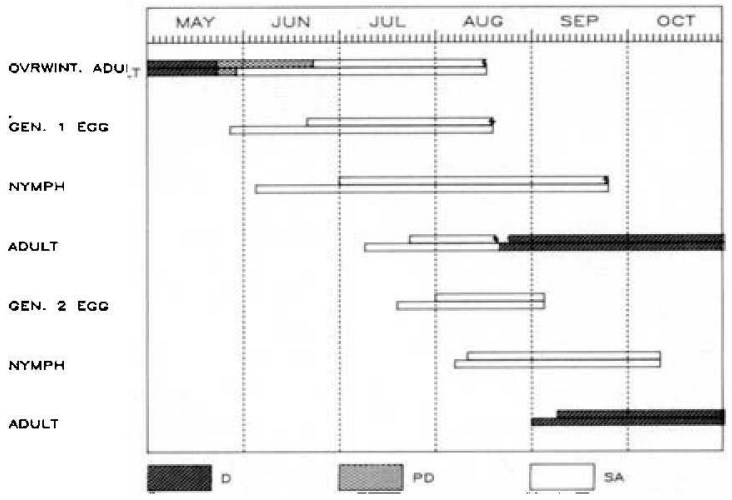

Fig. 2. Seasonal activity and voltinism in A. tristis. The upper bar of each pair is for 1984; the lower bar is for 1985. Broken lines at end of bars indicate estimated completion dates. Break between bars indicates that no data were available for this period. Legend: $D$, diapause; $\mathrm{PD}$, postdiapause inactive period; SA, seasonal activity (reproduction and development).

ferred to zucchini plants inside plastic cylinder cages. These were maintained in growth chambers (Forma Scientific, Marietta, Ohio) at $26.7 \pm 1^{\circ} \mathrm{C}$, $55 \% \mathrm{RH}$, and under a constant photoperiod similar to the natural daylength on that sample date (29 July, 15:9 (L:D); 14 August, 14.15:9.45). Subsequently, each pair was observed for mating or oviposition. Females that did not show signs of reproductive activity within $5 \mathrm{~d}$ of the sample date were dissected in a $1 \%$ solution of $\mathrm{NaCl}$ and examined for signs of diapause (i.e., absence of ovarial development, fat body accumulation).

In the later samples (30 August and 5 September), field-collected females were dissected directly in $1 \%$ saline and observed for evidence of diapause. Sexual maturity in males was assessed also by dissecting out testes in $1 \%$ saline and then preparing squash mounts on glass microscope slides. Observations were then made under $400 \times$ magnification for signs of sperm activity.

Sexual behavior in overwintering males was tested by confining males (sample date, 22 January) with both diapausing and nondiapausing females in the laboratory under $26.7 \pm 1^{\circ} \mathrm{C}, 55 \%$ $\mathrm{RH}$, and a long day length (16:8 photoperiod).

\section{Results}

Seasonal Occurrence. In 1984, adults were first observed on 17 June in a squash field near DeSoto, Kans. ( $11.2 \mathrm{~km}$ west of Kansas City). First egg masses were found at the same locality on 20 June. In 1985, adult bugs were first observed ovipositing on zucchini transplants on 27 May near Manhattan, Kans.

Oviposition by SB occurred on various cultivars of squash, zucchini, and pumpkins (Cucurbita mixta Pangalo and C. maxima), and on the weed C. foetidissima. However, field observations in- 
dicated that nymphal development on the weed was slow, and development past the second instar was not observed.

Voltinism and Seasonal Reproduction. The periods of activity for each $\mathrm{SB}$ generation in 1984 and 1985 are shown in Fig. 2. In 1984, first-generation progeny from the earliest overwintered adults began emerging on 21 July. Emergence of second-generation adults began on 7 September and continued until mid-October when host plants (i.e., pumpkin fruits) were no longer available to support the developing nymphs.

In 1985, first-generation adult emergence began on 9 July. Second-generation adults began emerging on 30 August. By 5 September, most of the emergence was completed.

In both years, first-generation adult females that emerged from early July to early August mated and oviposited readily. However, those adults emerging later in the season (e.g., late August) did not reproduce. Second-generation adults (late August-September emergence) also did not reproduce.

Seasonal Incidence of Diapause. In the 29 July sample, all but one of the first-generation adult female SB mated and oviposited within 3-4 d of transfer to the laboratory (Fig. 1). Dissection of this nonovipositing female (day 4) revealed large, mature ovaries and oviducts that contained chorionated eggs.

On the other hand, a small proportion $(17 \%)$ of the females from the 7 August sample entered diapause (Fig. 1). That is, neither mating nor oviposition was observed. Dissections of these females revealed small, undeveloped ovaries that were devoid of eggs. Also, the surrounding fat body was enlarged.

The percentage of emerging females that entered diapause increased as the season progressed. By the 5 September sample, $100 \%$ of the females entered diapause (Fig. 1). Microscopic examination of crushed testes showed that large numbers of motile sperm were present in SB males on each sample date. Moreover, the size, shape, and characteristic crimson red color of the testes did not vary over the sample period.

One component of male SB sexual behavior is a glandular display that is produced by everting the genitalia. This "calling" behavior, which was observed in the presence of diapausing females only, was absent in males from the late-August and early-September sample dates and from an overwintering population that was sampled on 22 January. In the January sample, mating with reproductively active females did not occur until $10 \mathrm{~d}$ after transfer to the laboratory $(\bar{x} \pm \mathrm{SD}=13 \pm 3 ; n=$ 6).

Period of Reproduction and Survivorship in Overwintered Adults. Fig. 3 shows the average daily oviposition and survivorship curves for overwintered SB females. In general, the number of eggs laid per day diminished throughout the sea-

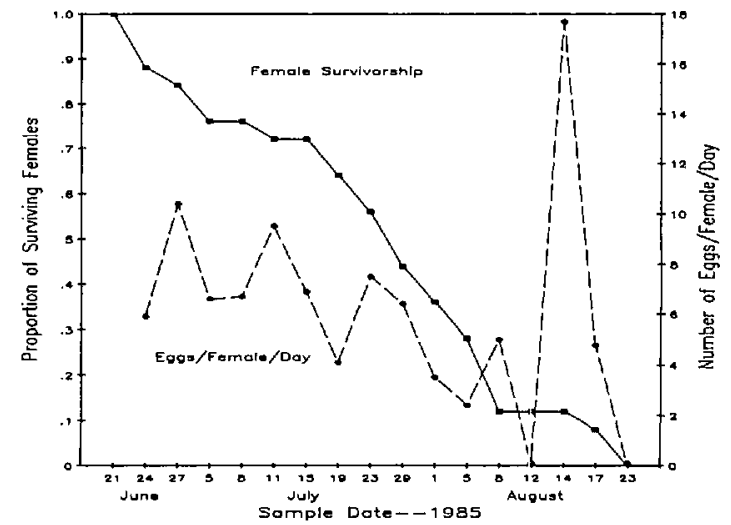

Fig. 3. Field survivorship and average daily oviposition schedule for overwintered A. tristis females. The initial cohort consisted of 25 females and 25 males.

son. However, the oviposition rate fluctuated in cycles of about $10 \mathrm{~d}$. In late June, females deposited an average of eight eggs per day (computed at the midpoint of the cycle). In early August, about two eggs per day were deposited. A large peak of oviposition occurred in early August (Fig. 3). Adult females were reproductively active until mid-August.

Survivorship of overwintered females declined steadily throughout the season, with $50 \%$ of the population remaining alive until late July (Fig. 3). The last females died between 17 and 23 August.

\section{Discussion}

Colonization of host plants was not observed before late May. However, mating and oviposition occurred at, or within a few days of, infestation (Fig. 2). Thus, reproductive diapause ends before adults disperse from overwintering quarters to host plants. These findings agree with recent experimental data that show that overwiritered SB adults terminate diapause in the field before late May (unpublished data). They also imply that differences in the seasonal occurrence of SB between years (Fig. 2) are not related to the timing of diapause termination but, instead, may depend on prevailing spring temperatures. For example, a prolonged period of below-average temperatures during the spring of 1984 (National Oceanic and Atmospheric Administration 1984) correlated with a 3-wk delay in initial infestation of plants compared with 1985 (Table 1).

The SB completes one and a partial second generation in Kansas. These generations overlap considerably (Fig. 2). In both 1984 and 1985, firstgeneration $\mathrm{SB}$ completed their life cycle in 5-6 wk; second-generation bugs required 7 wk. This difference may reflect a decline in the nutritional status of host plants as the season progresses; or, it may be related to the influence of physical factors 
Table 1. Mean temperature data for Manhattan, Kans., 1984-85

\begin{tabular}{lrrr}
\hline \multirow{2}{*}{ Month } & \multicolumn{3}{c}{ Temp $\left({ }^{\circ} \mathrm{C}\right)^{a}$} \\
\cline { 2 - 4 } & 1984 & 1985 & Avg $^{b}$ \\
\hline Jan. & -2.9 & -5.4 & -2.7 \\
Feb. & 5.2 & -2.2 & 0.7 \\
Mar. & 3.3 & 9.0 & 5.8 \\
Apr. & 10.7 & 14.9 & 13.0 \\
May & 16.9 & 20.0 & 18.5 \\
June & 23.7 & 21.5 & 23.7 \\
July & 25.4 & 26.3 & 26.6 \\
Aug. & 26.7 & 23.4 & 25.5 \\
Sept. & 20.2 & 19.7 & 20.7 \\
Oct. & 13.8 & 13.7 & 14.5 \\
Nov. & 7.7 & 2.3 & 6.3 \\
Dec. & 2.2 & -3.7 & 0.4 \\
\hline
\end{tabular}

a Data from National Oceanic and Atmospheric Administration (1984, 1985).

${ }^{b}$ Long-term average temperatures.

(e.g., temperature, relative humidity) on developmental rates.

Adult females that emerge during late August and early September enter diapause. Thus, SB females undergo a reproductive diapause in part of the first, and all of the second, generation. Firstgeneration females that mature before the beginning of August avoid diapause. However, the incidence of diapause increases thereafter and, by late August, all newly emerged fernales enter diapause. This includes females both from the end of the first generation and from the entire second generation. Reproduction does not take place until the following spring

Male SB apparently undergo diapause, but they do so with fully developed reproductive organs. Although motile sperm are present in the testes throughout the winter, sexual behavior (e.g., copulation attempts) is suppressed; in the laboratory the resumption of sexual behavior occurs after ca. 2 wk under long daylengths. This period is similar to the time required for field-sampled females to terminate diapause under the same conditions. These data suggest that diapause primarily affects reproductive behavior, rather than spermatogenesis, in SB males. Males of other insect species have also been shown to undergo a behavioral diapause with mature reproductive organs (see review by Pener \& Orshan [1983]; see Tauber et al. [1986]).

The environmental factors that induce diapause in SB are unknown. However, because adult bugs respond to photoperiod throughout their long period of diapause (unpublished data), this abiotic factor may also be important during diapause induction.

Overwintered females produce most of their eggs during June and early July (Fig. 3). However, because mature first-generation adults begin ovipositing by mid- to late July (Fig. 1), densities of immature SB remain at high levels during August.

Female survivorship declined at a steady rate throughout the season, but the average daily ovi- position rate fluctuated considerably between consecutive observation periods (Fig. 3). Because these data represent average oviposition responses, it is difficult to interpret these fluctuations. However, they may reflect cycles of oocyte maturation. They do not appear to be related to weather because an inspection of the daily climatological data ( $\mathrm{Na}$ tional Oceanic and Atmospheric Administration 1984, 1985) during the study period showed no apparent correlation between oviposition pattern and either temperature or precipitation. These observations differ from those of Beard (1940), who showed that individual SB females produced fewer eggs under cool, damp conditions than under hot, dry conditions. However, the Connecticut population that he worked with may have been subjected to a lower temperature range than the Kansas population.

The general seasonal decline in oviposition may reflect a progressive reduction in the daily oviposition per individual, or an increase in the proportion of nonovipositing females. Although daily oviposition data were not recorded for individual females, some females continued to oviposit until the day of death (see Fig. 3, days 225-230). Thus, the postreproductive (i.e., senescent) period in this insect may be short.

The long period of reproductive activity observed in overwintered SB females $(2.5 \mathrm{mo})$ is similar to that reported by Beard (1940) for overwintered SB from Connecticut. At both localities, adults emerged between late May and mid-June and continued to oviposit until about early August.

The large number of eggs that I observed at the end of the study is in sharp contrast to the earlier general decline (Fig. 3). These differences may indicate a shift in the proportion of females that oviposited. That is, a higher proportion of the latesurviving females may have oviposited than during the earlier observation periods.

High spring temperatures result in early oviposition and fast preimaginal development. Ultimately, this has two important conseqences for $\mathrm{SB}$ within-season population dynamics: large numbers of the early emerging first-generation adults avoid diapause; and a large number of these first-generation adults occur simultaneously with overwintered adults. These events combine to produce very large populations during midsummer. Conversely, delayed oviposition and development during cool springs reduce the overlap between generations and increase the proportion entering diapause. During those years, populations are smaller.

\section{Acknowledgment}

I thank J. L. Tracy, C. Armendariz, and W. Stewart for their assistance. I appreciate the helpful suggestions of the following individuals: L. L. Buschman and G. L. Greene (Kansas State University); M. J. Tauber and C. A. Tauber (Cornell University); and J. J. Obrycki (Iowa State University). W. C. Albrecht (Kansas State Univer- 
sity) assisted with the illustrations. The research was supported by Kansas Agricultural Experiment Station Hatch Project 546. This is Contribution No. 86-472-J from the Kansas Agricultural Experiment Station.

\section{References Cited}

Beard, R. L. 1940. The biology of Anasa tristis DeGeer, with particular reference to the tachinid parasite, Trichopoda pennipes Fabr. Conn. Agric. Exp. Stn. Bull. 440: 597-679.

Elliot, D. C. 1935. The squash bug in Connecticut. Conn. Agric. Exp. Stn. Bull. 368: 224-231.

National Oceanic and Atmospheric Administration. 1984. Record of river and climatological observations. U.S. Department of Commerce, Manhattan, Kans.
1985. Record of river and climatological observations. U.S. Department of Commerce, Manhattan, Kans.

Pener, M. P. \& L. Orshan. 1983. The reversibility and flexibility of the reproductive diapause in males of a "short day" grasshopper, Oedipoda miniata, pp. 67-85. In V. K. Brown \& I. Hodek [eds.], Diapause and life cycle strategies in insects. Junk, The Hague.

Tauber, M. J., C. A. Tauber \& S. Masalii. 1986. Seasonal adaptations of insects. Oxford, New York.

Worthley, H. N. 1923. The squash bug in Massachusetts. J. Econ. Entomol. 16: 73-79.

Received for publication 27 May 1986; accepted 3 November 1986. 